\title{
KOCH'S POSTULATES IN RELATION TO THE WORK OF JACOB HENLE AND EDWIN KLEBS
}

\section{K. CODELL CARTER*}

Among the essential elements of a theory of disease is the set of criteria that must be satisfied to establish that some specific factor is the cause of a particular disease. For example, in the germ theory various nonequivalent criteria have been proposed for establishing that specific micro-organisms cause particular diseases. ${ }^{1}$ Perhaps the most famous criteria are the conditions known as Koch's postulates.

The postulates are invariably mentioned even in superficial discussions of Robert Koch's work. However, different authors state the postulates differently, ${ }^{2}$ and many authors provide no evidence that they have read Koch; often the only justification for stating the postulates in a particular way is a superficial secondary work ${ }^{3}$ There is also disagreement about whether or not Koch adopted the postulates from his predecessors. Some commentators, assuming that Koch derived the postulates from Jacob Henle, refer to the postulates as the Henle-Koch postulates ${ }^{4}$ or even as the Henle postulates. ${ }^{5}$ Others deny that Henle significantly influenced Koch's thinking about causal criteria. ${ }^{6}$ Given that the postulates have been so influential, it is remarkable that there have been no serious attempts to resolve these issues.

This essay will first determine how Koch stated and used the postulates in some of his early papers. We will then examine the research tradition from which Koch seems to have derived the postulates, and argue that Edwin Klebs was a more important

${ }^{*}$ K. Codell Carter, PhD, Professor of Philosophy, Brigham Young University, Provo, Utah 84602, USA.

\footnotetext{
${ }^{1}$ For a survey of several sets of criteria see Alfred S. Evans, 'Causation and disease: the Henle-Koch postulates revisited', Yale J. Biol. Med., 1976, 49: 175-195.

${ }^{2}$ For example, contrast the following two versions: "(i) Isolate the organism suspected of causing the disease. (ii) Grow the organism in laboratory cultures. (iii) Inoculate a healthy animal with the cultured organism. See if the animal contracts the disease. (iv) If the animal contracts the disease, examine the animal and re-isolate the organisms that caused the disease." James H. Otto and Albert Towle, Modern biology, New York, Holt, Rinehart \& Winston, 1977, p. 196. “(i) The organism must be found in every case of the disease. (ii) The organism must not be found as an accidental or harmless parasite in other diseases. (iii) The organism, after its isolation from the body and cultivation in pure culture, must reproduce the same disease." Alex Sakula, "Robert Koch (1843-1910): founder of the science of bacteriology and discoverer of the tubercle bacillus', Br. J. Tuberc. Dis. Chest, 1979, 79: 391.

${ }^{3}$ For example, in an essay entitled 'Dr. Koch's postulates', Lester S. King bases his version of the postulates on Dorland's The American illustrated medical dictionary (J. Hist. Med., 1952, 7: 350-361, pp. $351 \mathrm{f}$.).

4 For example, Evans, op. cit., note 1 above.

5 "Henle's Postulates were redrawn in scientific terminology as Koch's Postulates." Phyllis A. Richmond, 'The germ theory of disease', in Abraham M. Lilienfeld (editor), Times, places, and persons, Baltimore, Md., Johns Hopkins University Press, 1980, p. 85.

${ }^{6}$ For example, Raymond N. Doetsch, 'Henle and Koch's Postulates', ASM News, 1982, 48: $555 f$.
} 


\section{K. Codell Carter}

source than was Jacob Henle. Finally, we will consider one way in which Koch's postulates differ from both Klebs' and Henle's causal criteria. I will argue that whereas Klebs' and Henle's criteria for disease causation are satisfied by causal agents that are only causally sufficient, Koch's postulates stipulate that causes of disease must also be causally necessary.

Much of my argument rests on the distinction between causal necessity and causal sufficiency and, since these terms are frequently misused, I will explain how they are to be understood in this paper. For our purposes, a phenomenon $C$ is sufficient for a phenomenon $E$ if the occurrence of $C$ ensures the occurrence of $E$. A phenomenon $C$ is necessary for a phenomenon $\mathrm{E}$ if the nonoccurrence of $\mathrm{C}$ ensures the nonoccurrence of E. It is obvious, but frequently overlooked, that if one wants to bring about some state of affairs, or to explain something that has happened, one seeks a sufficient cause, since by bringing that cause to bear one can be certain that the desired effect will follow. On the other hand, if one wants to prevent or to eliminate some state of affairs, or to explain why something did not happen, one seeks a necessary cause, since by preventing that cause one can prevent the undesired effect. Thus, the subtle change from sufficiency criteria to criteria for causal necessity may reflect fundamental changes in the purposes and goals of medical discussions of disease causation.

Over the course of his career, Koch employed different criteria for establishing causality. The postulates appear in only a few of Koch's more than one hundred published papers, and, with the exception of one 1890 publication, ${ }^{7}$ all the papers in which Koch mentioned or explicitly used the postulates appeared between 1878 and 1884. There are major differences in Koch's own statements of the postulates. We will begin by examining Koch's causal criteria in three groups of publications: (i) his first two anthrax papers (1876 and 1881); (ii) his two 1878 papers on wound infections; and (iii) certain papers published between 1882 and $1884 .^{8}$

Koch's first important paper (1876) concerned the aetiology of anthrax. ${ }^{9} \mathrm{He}$ reported the first successful attempt to trace the life cycle of a bacillus, described some technical innovations such as the suspended-drop method for culturing bacilli, and argued that a specific bacillus, Bacillus anthracis, was the cause of anthrax. This paper contains no discussion of criteria for proving disease causality. Yet Koch felt he had proved that Bacillus anthracis was the cause of anthrax, ${ }^{10}$ and by examining his.

\footnotetext{
'This paper was 'Ueber bakteriologische Forschung'; it is in J. Schwalbe (editor), Gesammelte Werke von Robert Koch, Leipzig, Georg Thieme, 1912, vol. 1, pp. 650-660.

- In his papers on cholera and in the paper on bacteriological research Koch used yet other versions of the postulates. After 1890, he continued to presuppose causal criteria, but he did not use the postulates at all. However, for our purposes it is unnecessary to examine these sources.

9 'Die Aetiologie der Milzbrandkrankheit, begrundet auf die Entwicklungsgeschichte des Bacillus Anthracis', Schwalbe op. cit., note 7 above, pp. 5-26.

${ }^{10}$ Koch frequently made comments such as this: "Until now [1882] a proof [that some disease is due to a micro-organism] has been completed only for anthrax. For many other human infectious diseases, for example, recurrent fever, the infected wound diseases, leprosy, gonorrhoea, only the simultaneous occurrence of parasites and a pathological process is known, but the causal connexion has not been proven." 'Die Aetiologie der Tuberkulose', ibid, pp. 428-455, p. 444.
} 


\section{Koch's postulates in relation to the work of Henle and Klebs}

arguments it is possible to identify the criteria that he presupposed.

In his 1876 anthrax paper, Koch provided no significant original evidence that bacilli were either necessary or sufficient for natural anthrax. His discussion rested almost exclusively on artificially induced anthrax in test animals. Koch mentioned that he had often examined animals that died of natural anthrax (i.6). ${ }^{11}$ However, of those examinations he reported only that he found bacilli in the spleen of an anthrax horse-the only horse he had examined (i.21). Koch cited earlier researchers who identified bacilli in natural cases, but he also mentioned other investigators who did not find them.

As Koch explained in the introduction to his 1876 paper, his study was based on the work of Casimir Davaine. Davaine's results were generally regarded as the strongest evidence that anthrax was caused by Bacillus anthracis. Davaine's argument was an argument for causal necessity; he reported that he always found minute rods in the blood of anthrax animals, and that inoculations with blood that did not contain the rods would not cause anthrax. ${ }^{12}$ Koch did not have access to Davaine's original papers (i.105); he knew Davaine's work from abstracts which clearly presented Davaine's argument as an argument for causal necessity. ${ }^{13}$ In harmony with the abstracts, Koch noted that "[Davaine] asserted that the rods were bacteria and that anthrax could occur only if these rods from anthrax blood were present" (i.5). As Koch here described it, Davaine's view was that the rods were necessary for anthrax. One objection to Davaine's view was that anthrax sometimes seemed to have been caused by inoculations with bacteria-free blood. If so, this would have shown that the rods were not necessary. Koch answered this objection by arguing that the inoculated blood must have contained bacilli spores (i.18). Since spores were difficult to detect, one could reasonably assume that earlier researchers had overlooked them. Thus, by explaining earlier failures to find bacilli, Koch defended Davaine's thesis that they were necessary for the disease.

Thus, the context of Koch's work suggests that he was mainly interested in proving that the bacilli were necessary for anthrax. This is also how Koch himself stated his argument. He reported that he repeatedly sought to generate anthrax by inoculations with anthrax materials that contained no bacilli, with hay-infusion bacilli, and with "a species of bacillus that developed spontaneously and that was very similar to Bacillus anthracis" (i.18). Since these experiments failed, Koch concluded that a substance could generate anthrax only if it contained anthrax bacilli or their spores. "Anthrax substances, whether fresh, decayed, or dried, can only cause anthrax if they contain Bacillus anthracis or its viable spores. This removes all doubt that Bacillus anthracis is

\footnotetext{
${ }^{11}$ To reduce the footnotes I consistently refer to Koch's collected works, ibid., in this way by volume and page.

${ }_{12}$ Davaine's most important results were announced in a series of papers in Comptes rendus de l'Académie des Sciences in 1863 and 1864.

${ }^{13}$ For example, Friedrich Steudener pointed out that Davaine found anthrax rods in the blood of all the animals that died of anthrax. He observed that "Davaine regarded these organisms as the actual cause of anthrax. Through their vegetation they destroyed the blood in a process similar to fermentation. He supported this view especially by inoculation experiments. Only blood that contained the bacilli could convey anthrax." Friedrich Steudener, 'Ueber pflanzliche Organismen als Krankheitserreger', Samml. klin Vortr., Innere medizin, 1872, 1: 38: 283-308. pp. 303f. This argument establishes causal necessity and it is precisely like the argument Koch gave in his first anthrax paper. Koch knew Steudener's paper; he cited it in his essay on the infected wound diseases.
} 


\section{K. Codell Carter}

the actual cause and contagium of anthrax." (i.21f). In this passage, Koch infers that bacilli cause anthrax from the observation that anthrax occurs only if injected substances contain bacilli or spores. Thus, he is presupposing necessity as the criterion for identifying the cause of anthrax. Here, and in other passages, Koch clearly regards necessity as decisive in establishing causality (e.g., i.19).

By contrast, Koch seems not to have regarded sufficiency as equally significant. First, he knew that the mere presence of anthrax bacilli in an animal did not ensure that it would become diseased; ingesting anthrax bacilli did not invariably induce anthrax (i.19), some inoculation procedures were unreliable (i.6), and even among exposed susceptible animals, vulnerability depended on various factors (i.213). So Koch could not claim that the bacilli alone were sufficient to cause anthrax. As we will see, in later papers Koch adopted various causal criteria that were similar to but weaker than strict sufficiency. However, in the early anthrax papers one finds no such criteria. After some early failures, Koch developed inoculation procedures that invariably induced fatal anthrax in certain test animals. But in describing his procedure, he observed only that it was important because it provided a test for the viability of bacilli cultures (i.7). Nowhere in the 1876 paper did he suggest that these inoculations, which reliably killed test animals, provided direct evidence that the bacilli were the cause of anthrax. The fatal inoculations certainly influenced Koch's thinking, but as he himself stated his argument, he seems to have been most influenced by the unsuccessful inoculations with anthrax substances that contained neither bacilli nor spores. Thus, Koch seems not to have regarded sufficiency as central in proving that the bacilli were the cause of anthrax.

This conclusion is supported by Koch's remarks in his second anthrax paper (1881).${ }^{14}$ He quoted the passage discussed above, in which he concluded that the bacilli were the cause of anthrax because only substances containing them induced anthrax (i.175). After reviewing some additional evidence, he concluded, "thus, anthrax never occurs without viable anthrax bacilli or spores. In my opinion no more conclusive proof can be given that anthrax bacilli are the true and only cause of anthrax." (i.184). Here, as in the 1876 paper, his conclusive proof of causality is that bacilli or spores are necessary. Koch acknowledged that critics "demand that inoculated bacilli be totally removed from any associated substances that may contain dissolved disease materials." But, Koch responded, "this is impossible . . .. No one can take seriously such an undertaking." Here he rejected as impossible the demand to prove that inoculated bacilli were sufficient; he then insisted again that his earlier arguments, which established necessity but not sufficiency, "prove as conclusively as possible that bacilli are the disease material".

All of this suggests that in his initial work on anthrax Koch's main criterion for proving causality was showing that inoculated substances were effective only if they contained bacilli or spores, that is, showing that either bacilli or spores were necessary for artificial cases of disease.

Koch published two papers on wound infections. He first summarized his work in a lecture in the 1877 meetings of the Gesellschaft deutscher Naturforscher und

\footnotetext{
${ }^{14}$ Koch, 'Zur Aetiologie des Milzbrandes', Schwalbe, op. cit., note 7 above, pp. 174-206.
} 


\section{Koch's postulates in relation to the work of Henle and Klebs}

Aerzte. ${ }^{15} \mathrm{He}$ then published a long paper on the same subject. ${ }^{16}$ These papers, which were both published in 1878 , are significantly different and we will consider them separately.

Koch began the summary paper by observing that the regular discovery of micro-organisms in infected wounds did not imply that these diseases "come about only when organisms enter the body and proliferate there, in other words, that the diseases are parasitic. This is because in many cases of unquestionably infectious diseases either no organisms are found or too few are found to explain the symptoms or the fatal termination of the disease." (i.58). Here again, as Koch described it, the issue is whether the organisms are necessary. Koch explained that he conducted inoculation experiments to appraise these objections to the parastic conception. He reported that by using ordinary techniques he was able to identify organisms in only a few test animals, and these results were, therefore, inconclusive. However, by using new staining and illumination techniques, which he had developed, he could identify micro-organisms in every case (i.58f).

In the summary paper, Koch's main goal seems to have been to establish that micro-organisms were necessary for wound infections by explaining why earlier researchers sometimes failed to find them and by developing reliable techniques for identifying them. Koch discussed his inoculation experiments, but, as in the anthrax papers, he seems not to have regarded them as central in establishing causality. He reported that the inoculations were useful in providing diseased animals in which organisms could be demonstrated; he also observed that the inoculations proved that the wound diseases were indeed infectious. He did not cite these experiments in his argument for causality. In the summary paper, therefore, as in the first anthrax papers, Koch seems to have been principally concerned with establishing that micro-organisms were necessary.

In his long paper on wound infections, for the first time, Koch explicitly mentioned criteria for disease causality. These criteria are the first version of the postulates. He wrote that a conclusive proof of the parasitic origin of some disease "would require that we find parasitic organisms in all cases of the disease, that they are present in such numbers and distribution that the disease symptoms can be explained, and that a morphologically distinguishable organism is identified for every different disease." (i.75). Thus, Koch specified these three criteria:

I.1. The micro-organism must be exhibited in all cases of the disease.

I.2. The distribution of the micro-organism must correlate with and explain the disease phenomena.

I.3. For each different disease, a morphologically distinguishable micro-organism must be identified.

Koch mentioned the same criteria in another passage, and he identified I.1 and I.2 in a third passage as well (i.100, 72).

The first criterion requires that the micro-organism is necessary for the disease; this is the condition that seems to be central in Koch's 1876 and 1881 anthrax papers. I.2. requires no discussion in this context. However, I.3 requires attention.

${ }^{15}$ Koch, 'Neue Untersuchungen über die Mikroorganismen bei infektiösen Wundkrankheiten', ibid., pp. 57-60.

${ }^{16}$ Koch, 'Untersuchungen über die Aetiologie der Wundinfektionskrankheiten', ibid., pp. 61-108. 


\section{K. Codell Carter}

To avoid circularity, it must be possible to distinguish parasitic organisms in some way other than by the disease they supposedly cause. But different diseases could be caused by morphologically indistinguishable organisms. ${ }^{17}$ One might imagine, for example, that the only difference between two kinds of bacilli is that they produce slightly different toxins which affect their hosts differently. Thus, we must broaden I. 3 to include more than morphological differences. This is compatible with Koch's later thinking; in 1884, he wrote that "morphological characteristics are not normally sufficient to distinguish bacteria" (ii.61), and in 1890, he insisted that every possible characterisitic of different strains of organisms be considered before identifying them as of the same species (i.652f). Thus, I.3 changes through the course of Koch's career. Yet all the versions of I.3 contrast so sharply with some of Koch's other criteria, which we will later examine, that we will ignore these changes and simply restate $I .3$ in such a way as to avoid the defect we have mentioned and to make it compatible with Koch's later thinking:

I.4. The micro-organism must be distinguishable in some way from organisms that are associated with other diseases.

We will take I.4 as the correct statement of Koch's third criterion.

We must now determine how I.4. relates to the claim that a given organism is sufficient for some disease. If an organism is strictly sufficient for a given disease, whenever the organism is present the disease must occur. Thus, the organism could not occur nonpathogenically or as the cause of some other disease. But to prove that the organism always leads to the given disease, the organism must be distinguishable in some way from every other organism, that is, I.4 must be satisfied. Thus, I.4 follows from strict sufficiency. On the other hand, an organism might satisfy I.4 and still not be sufficient for any disease. There are two important possible counterinstances: first, distinguishable organisms that are usually pathogenic might sometimes occur nonpathogenically. Koch sometimes denied that bacteria can ever be found in healthy tissues (i.71f); if true, this would exclude the nonpathogenic occurrence of bacteria. At this point in his career, however, Koch had no conclusive evidence regarding the possibility that ordinarily pathogenic organisms could occur nonpathogenically ${ }^{18}$ perhaps for this reason, his remarks in this paper are inconclusive. Second, the disease agent might not be the organisms themselves but a substance with which they are always associated in diseased animals. Neither Koch's suspended-drop method nor passing cultures through animal bodies could exclude this possibility because, in addition to bacteria, liquid media could always contain trace substances from the original diseased animal. Here again, I.4 could be true but the micro-organisms themselves still might not be sufficient. In subsequent papers, Koch acknowledged both of these possibilities. However, in the 1878 papers, his remarks are inconclusive; one cannot be sure exactly how much of this Koch himself understood at the time. The important point is that I.4 follows from but does not imply strict sufficiency; it is a weaker condition.

It will be useful to refer to I.4, and to certain other criteria that Koch subsequently introduced, as "weak sufficiency criteria"; this phrase, of course, reflects the logical

${ }^{17}$ One of Koch's reviewers, C. Hueter, pointed this out in Dt. Z. Chir., 1879, 11: 389-399, p. 396.

${ }^{18}$ Apparently, Koch first discovered the phenomenon of healthy carriers in about 1893 (ii.168f, 215 , 920). 


\section{Koch's postulates in relation to the work of Henle and Klebs}

relation between each of these criteria and the logically stronger principle of strict sufficiency.

Koch's discussion of each infected wound disease is loosely organized around his three criteria. For each disease, Koch identified a particular organism and showed that its distribution in a diseased animal explains the pathological alterations, some of the symptoms, and the death of the animal. To some extent this confirms I.2 and I.4. As in the summary version of his paper, Kock also attributed earlier failures to identify the organisms to technical inadequacies, and he suggested that his improved procedures would reveal organisms in all cases (i.100f). This part of his argument, exactly like the arguments in his anthrax papers, indirectly supports the claim that micro-organisms are necessary by explaining some apparent counter-evidence. It is obvious, however, that Koch's evidence I.1 and I.4 is relatively weak. In this paper, as in his anthrax papers, Koch's discussion rests almost exclusively on inoculation experiments. He never argues that natural infections involve the organisms he considers, and he can apply his results to human infections only with an argument by analogy $(\mathrm{i} .61,100)$. This may partially explain why, in contrast to what he wrote about anthrax and tuberculosis, Koch never claimed that his work on infected wounds conclusively established causality.

Koch announced the discovery of the tuberculosis bacillus in a paper delivered in 1882.19 This sensational discovery probably did as much as any single accomplishment to establish the domination of the germ theory. Later in 1882, Koch published a second paper on tuberculosis. ${ }^{20}$ Other papers appeared over the next two years culminating in Koch's monumental 1884 paper on the aetiology of tuberculosis. ${ }^{21}$ In these papers, he meticulously followed specific criteria for establishing disease causality; these criteria were similar to but slightly different from those he employed in the paper on infected wound diseases. Their centrality in Koch's reasoning in his famous and eminently influential tuberculosis papers ensured that they would profoundly influence subsequent aetiological thought.

In the first tuberculosis paper, Koch observed that "the goal of the investigation is first to exhibit certain parasitic forms that are foreign to the body and that could possibly be the cause of the disease." (i.429). As in earlier papers, Koch introduced techniques that enabled him to identify the parasitic bacillus, and he explained earlier failures to identify it (i.432f). Koch reported finding the bacillus in materials from dozens of natural cases of human and animal tuberculosis and in approximately two hundred animals that has been inoculated with tuberculous materials. $\mathrm{He}$ concluded that "tubercle bacilli occur in all tuberculosis disorders of humans and animals" (i.433). Up to this point, Koch has argued that the bacilli are necessary for the disease. Next, he observed that the bacilli "are distinguishable from all other micro-organisms". Thus the unique organisms associated with tuberculosis satisfy I.4. ${ }^{22}$

${ }^{19}$ Koch, op. cit., note 10 above.

${ }^{20}$ Koch, 'Ueber die Aetiologie der Tuberkulose', Schwalbe, op. cit., note 7 above, pp. 446-453.

${ }^{21}$ Ibid., pp. 467-565.

${ }^{22}$ If so, however, Koch's argument is defective. I.4 stipulated that each causal agent must be distinguishable from organisms associated with other diseases. But what Koch called tuberculosis included such different disorders as scrofula and phthisis, which, as he knew, were caused by the same organism. I.4 


\section{K. Codell Carter}

In both 1882 papers, Koch observed that establishing a regular coincidence between a disease and a specific organism does not prove causality. Indeed, he noted, even identifying the organism in the organs where the disease is known to originate is not conclusive (i.433). Of various possible strategies for proving causality, Koch proposed to use a method that began by isolating the suspected disease agent in pure culture. One could then demonstrate that the agent was a living parasitic organism. "It then remains to prove that the isolated parasite is really the cause of the disease. To accomplish this, one must show that animals inoculated with the pure culture contract the original disease. The inoculation must succeed not only sometimes but in every attempt as is achieved in such infectious diseases as anthrax." (i.446f). In substantial sections of both 1882 papers, Koch reported his attempts to inoculate tuberculous materials and cultures. The effort that he devoted to this part of the argument, together with his own explicit assertions, show clearly that Koch regarded this as the most decisive step in identifying the cause of tuberculosis. After reporting his inoculation experiments, Koch concluded "these facts, taken together, show that the bacilli in tuberculous substances are not merely coincidental with tuberculosis, but cause it. These bacilli are the real tuberculosis virus." (i.442).

In 1882, Koch also published a paper criticizing Pasteur's attempts to immunize animals against anthrax. ${ }^{23}$ In this paper, Koch described his own method of studying infectious disease, and he contrasted his method with Pasteur's. Koch claimed to begin by examining "all the body parts that are altered by the disease to establish the presence of the parasites, their distribution in the diseased organs, and their relation to the body tissues." (i.208). However, this investigation merely provided an orientation, after which one could "begin to demonstrate that the organisms are pathogenic and that they are the cause of the disease. For this purpose they must be cultured pure and, after they have thereby been entirely freed from all the parts of the diseased body, they must be inoculated back into animals, preferably of the same species as those in which the disease was originally observed." Koch mentioned tuberculosis as a disease in which these criteria had been fully satisfied. Thus, in this 1882 anthrax paper, Koch endorsed the same criteria for causality as in the tuberculosis papers that appeard in the same year. Yet, as we have seen, he did not actually follow these steps in identifying the cause of anthrax; his 1876 and 1881 papers reveal a significantly different strategy.

In 1883 , Koch published a response to criticisms of his work on tuberculosis. ${ }^{24}$ In this paper, he did not explicitly discuss causal criteria, but he clearly held the same conception of causation as that advanced in his 1882 tuberculosis and anthrax papers. $^{25}$

Koch's monumental 1884 paper, 'Die Aetiologie der Tuberkulose', contains his

could only be satisfied by characterizing tuberculosis aetiologically. Koch may have been sensitive to this problem (cp. i. 508). He admits that the same situation obtained with respect to anthrax (i.470).

${ }^{23}$ Koch, 'Ueber die Milzbrandimpfung', Schwalbe, op. cit., note 7 above, pp. 207-231.

${ }^{24}$ Koch, 'Critische Besprechung der gegen die Bedeutung der Tuberkelbazillen gerichteten Publikationen', ibid., pp. 454-466.

${ }^{25}$ This paper also contains suggestions that tubercule bacilli may be strictly sufficient. Koch observed, for example, that while bacilli were found in "well over one thousand" tuberculosis cases, they "were never found in numerous control investigations of healthy persons." (i.455). 


\section{Koch's postulates in relation to the work of Henle and Klebs}

most complete discussion of causal criteria; his position was the same as in the earlier tuberculosis papers.

First it is necessary to determine whether the diseased organs contain elements that are not constituents of the body or composed of such constituents. If such alien structures can be exhibited, it is necessary to determine whether they are organized and show signs of independent life. Such signs include motility-which is often confused with molecular motion-growth, propagation, and fructification. It is also necessary to consider the relation of such structures to their surroundings and to nearby tissues, their distribution in the body, their occurrence in various states of the disease, and so forth. Such considerations enable one to conclude that there is probably a causal connexion between the structures and the disease. Facts gained in these ways can provide so much evidence that only the most extreme sceptic would still object that the organisms may not be the cause, but only a concomitant of the disease. Often this objection has a certain justice, and, therefore, establishing the coincidence of the disease and the parasite is not conclusive. In addition, one requires a direct proof that the parasite is the actual cause. This can only be achieved by completely separating the parasites from the diseased organism and from all products of the disease that could be causally significant. If the isolated parasites are then introduced into healthy animals they must cause the disease with all its characteristics. (i.469f). ${ }^{28}$

Koch used anthrax to illustrate these conditions (i.470).

These criteria are the same as those in the earlier tuberculosis papers; they can be summarized as follows:

T.1. An alien structure must be exhibited in all cases of the disease.

T.2. The structure must be shown to be a living organism and must be distinguishable from all other micro-organisms.

T.3. The distribution of micro-organisms must correlate with and explain the disease phenomena.

T.4. The micro-organism must be cultivated outside the diseased animal and isolated from all disease products which could be causally significant.

T.5. The pure isolated micro-organism must be inoculated into test animals and these animals must then display the same symptoms as the original diseased animal.

T.I and T.2 correspond to I.1 and I.4; together they stipulate that the organism is necessary for the disease and that different organisms can identified for different diseases. T.3 is the same as I.2.

In the 1882 and 1884 papers, Koch regarded T.4 and T.5 as most decisive. We must determine how these criteria relate to I.4. As we have seen, I.4 does not stipulate that the organism is sufficient for the disease in question; given I.4, it is possible either that the organism is sometimes nonpathogenic, or that the cause is not actually the organism itself but rather some substance with which the organism is regularly associated in diseased bodies. In the 1881 anthrax paper, Koch insisted that it would be impossible to exclude this second possibility (i.184). However, by 1882 , Koch's use of solid culture media produced results that were more reliable and more conclusive than those obtained from the liquid media previously in use. His new techniques enabled him to do precisely what, one year earlier, he had rejected as impossible - to isolate bacilli from every contaminating influence and to inoculate material that, for all practical purposes, consisted of pure bacilli. Yet, even with his improved technology, Koch could not prove that ordinarily pathogenic organisms

${ }^{26}$ Koch gave a similar list of criteria at (i.517). Here, as at (i.455), he suggested that tubercle bacilli may be strictly sufficient. 


\section{K. Codell Carter}

were never nonpathogenic. Indeed, in the tuberculosis papers, he admitted that tubercle bacilli could sometimes exist in a suitable host without causing the disease (i.443f). Thus Koch still could not stipulate that the bacilli were sufficient for tuberculosis.

Koch had found inoculation procedures that reliably produced anthrax, tuberculosis, and the infected wound diseases. Thus, in each of these cases if the organisms were introduced in the proper way, they were always pathogenic. Having used solid media to determine that the organisms themselves were the causal agent, this meant that properly inoculated organisms were strictly sufficient. T.5 generalizes this condition; it stipulates that for each disease there must be an inoculation procedure that will always produce the disease.

Koch knew that $T .5$ could be satisfied even by organisms that were not themselves strictly sufficient for the disease they caused; in spite of the reliable inoculation procedure for tuberculosis, the presence of tubercle bacilli was not sufficient for the disease (i.443f). On the other hand, if the presence of some organism were strictly sufficient for some disease, inoculating the organism would always produce the disease. Thus, once again Koch has identified a causal criterion that is logically weaker than strict sufficiency. T.5 and I.4 are both implied by strict sufficiency, but they probably bear no logical relation to each other. It is imaginable that separate cultures of indistinguishable organisms could reliably induce different diseases when inoculated into animals. If so, of course, one would assume that there was some difference between the cultures, but T.5 could be satisfied even if no difference could be found. Thus, given T.5, it is possible for I.4 to be false. Similarly, given I.4, the disease could still be caused by a substance other than the organisms themselves and, therefore, there might be no way of inoculating pure bacilli to produce the disease. Thus, given I.4, it is possible for T.5 to be false. Koch apparently regarded I.4 and T.5 as logically independent; otherwise there would have been no reason to include I. 4 in his statement of T.2 while, at the same time, including T.5 as a separate condition. But, while I.4 and T.5 may be independent, unlike I.4, T.5 excludes the possibility that some factor other than the organism is the causal agent. In this sense, T.5 can be regarded as stronger than I.4; this may explain why Koch favoured T.5.

In the 1882,1883 , and 1884 papers, for the first time, Koch gave significant attention to natural cases of disease. Thus, the tuberculosis papers are less dependent on inoculation tests than are the earlier papers. Nevertheless, in the tuberculosis papers Koch insisted that T.4 and T.5 were most decisive. T.1, T.2, and T.3, which alone involved natural cases of disease and which he had earlier taken as conclusive, he now believed to show only that the organism is probably the cause. ${ }^{27}$ Yet Koch never abandoned T.1, T.2 and T.3. Each tuberculosis paper reports evidence that the bacilli are necessary and can explain the disease phenomena.

\footnotetext{
${ }^{27}$ It is not entirely clear what Koch meant in saying that one criterion is most decisive. Presumably, each criterion is necessary and they are jointly sufficient. Thus, no one criterion alone can prove causality. He probably adopted this way of speaking from some of his contemporaries who also used T.4 and T.5 and who seem to have regarded them as conclusive.
} 
By the middle of the nineteenth century, pathological anatomy had produced several schools of thought which collectively dominated European medical research. Rudolf Virchow was a leading contributor to one branch of this research tradition. ${ }^{28}$ In 1847, in the first issue of his famous Archiv, Virchow discussed the methods and goals of what he called scientific medicine ${ }^{29} \mathrm{He}$ asked, "How can one decide with certainty which of two coexistent phenomena is the cause and which the effect, whether one of them is the cause at all instead of both being effects of a third cause, or even whether both are effects of two entirely unrelated causes?" ${ }^{30} \mathrm{He}$ observed that such questions could be answered "partly by observation ... and partly by animal experiments". ${ }^{31}$ Of these, "experiment is the final and highest court . . . for experiment alone is equally accessible to the entire world of medicine, and experiment alone shows the specific phenomenon in its dependency on specific conditions, for these conditions are arranged by choice." Similar ideas can be found in the writings of many of Virchow's contemporaries.

Virchow regarded diseases as characteristic physiological processes resulting from altered or abnormal influences on the body..$^{32}$ In his view, one important goal for pathological anatomy was tracing the development of such morbid processes. ${ }^{33} \mathrm{Thus,}$ Virchow and his colleagues frequently applied his strategy for determining causation in showing that a particular lesion was the cause of other morbid changes. In such an investigation, one usually examined corpses which revealed different stages of the disease process, and one sought to induce similar processes in animals. Virchow believed that particular internal lesions could be caused by different external influences, but his work focused on the internal morbid process and, as he admitted, he seldom gave attention to the external influences which initiated such processes. ${ }^{34}$ Of course, Virchow's general strategy for establishing causality could also be used to identify these external influences.

In a discussion published in 1840 , Jacob Henle, who was also a pathological anatomist, proposed a criterion for identifying external disease causes. This criterion conformed perfectly with the general strategy that Virchow subsequently discussed. Henle conjectured that many diseases may be caused by parasitic micro-organisms. ${ }^{35}$

\footnotetext{
${ }^{28}$ For a discussion of Virchow's relation to the research tradition of pathological anatomy see L.J. Rather, 'Rudolf Virchow's views on pathology, pathological anatomy, and cellular pathology', Arch Path, 1966, 82: 197-204.

${ }^{29}$ Rudolf Virchow, 'Ueber die Standpunkte in der wissenschaftlichen Medicin', Virchows Arch. path. Anat. Physiol., 1847, 1: 3-19. This paper is translated in Lelland J. Rather, Disease, life, and man, Stanford University Press, 1958, pp. 26-39.

30 Ibid., p. 15.

31 Ibid., p. 17.

${ }^{32}$ Virchow said things like this in many of his essays. For example, ibid., p. 3. There is a more complete discussion in Rudolf Virchow, Gesammelte Abhandlungen zur wissenschaftlichen Medicin, Frankfurt, Meidinger, 1856, pp. 36-53.

${ }^{33}$ See, for example, Virchow's illustrations of how one determines causality in Virchow, op. cit., note 29 above, pp. $17 f$.

${ }^{34}$ Virchow admitted this in response to criticism by Edwin Klebs. See Rudolf Virchow, 'Krankheitswesen und Krankheitsursachen', Virchows Arch. path. Anat. Physiol., 1880, 79: 1-19, pp. 9f.

${ }^{35}$ Jacob Henle, Pathologische Untersuchungen, Berlin, A. Hirschwald, 1840, p. 43. George Rosen translated the most relevant part of Henle's book, 'On miasmata and contagia', Bull. Hist. Med., 1938, 6:
} 


\section{K. Codell Carter}

However, he noted that even if one regularly found living organisms in contagious fluids within diseased bodies, one could still not infer that the organisms were more than harmless saprophytes. The contagion could still be the fluids themselves rather than the organisms. According to Henle, "one could prove empirically that [the organisms] were really effective only if one could isolate... the contagious organisms from the contagious fluids, and then observe the powers of each separately. ${ }^{, 36}$ Henle was sceptical about the possibility of carrying out such a proof, ${ }^{37}$ and apparently he never tried to do so. His research, like that of Virchow and the other pathologists, focused on internal disease processes, and he gave little attention to external factors, such as invading micro-organisms, in response to which diseases might originate. Yet Henle's criterion rests on generating artificial disease processes in animals and, therefore, it conforms to the general research strategy that Virchow described. Henle's criterion is also significant since it anticipated T.4 and T.5.

Partly because pathological anatomy focused on internal processes rather than on external causes, medical researchers in the nineteenth century gave little attention to micro-organisms as possible causes of diseases. One exception was Karl Mayrhofer who, in the early $1860 \mathrm{~s}$, published a series of papers arguing that certain organisms, which he called vibrions, were the cause of puerperal fever ${ }^{38}$ To prove that the organisms were the cause, and not merely harmless concomitants of the disease, Mayrhofer tried to isolate them from other disease products and to introduce them into healthy rabbits. ${ }^{39}$ Given available technology, Mayrhofer came close to satisfying Henle's criterion. Both Mayrhofer and Carl Braun who was the professor of obstetrics under whom Mayrhofer did his work, cited Henle's conjecture that various diseases could be due to micro-organisms. ${ }^{40}$ Thus, while Mayrhofer did not specifically associate his experiments with the procedure that Henle discussed, he may have been aware of Henle's remarks. In any case, Mayrhofer's work conformed to the empirical standards of observation and experimentation by which his contemporaries sought to establish causal relations.

In the late $1860 \mathrm{~s}$, several researchers reported identifying micro-organisms in specific disease processes. ${ }^{41}$ After Mayrhofer, Edwin Klebs was among the first who tried to prove experimentally that these organisms were causal agents. Klebs had been Virchow's pupil, and during the 1860 s, he published several papers that were

911-983. Henle also considered this possibility in his Handbuch der rationellen Pathologie, Berlin, A. Hirschwald, 1851, vol. 2., pp. 459-480.

${ }^{36}$ Ibid., p. 43.

${ }^{37}$ Immediately after the sentence just quoted, Henle observed that there is no way in which such an experiment could be performed.

${ }^{38}$ Mayrhofer's most important work was 'Zur Frage nach der Aetiologie der Puerperalprocesse', Mschr. Geburtsk. Frauenkr., 1865, 25: 112-134.

${ }^{39}$ Karl Mayrhofer, 'Untersuchungen über Aetiologie der Puerperalprocesse', Med. Jb., 1863, 19: 28-42.

${ }^{40}$ Mayrhofer, op. cit., note 38 above, p. 115; Karl Braun, 'Kindbettfieber', in John Baptist Chiari, Karl Braun, and Joseph Spaeth, Klinik der Geburtshilfe und Gynaekologie, Erlangen, Ferdinand Enke, 1855 , p.480.

${ }^{41}$ For a review of the literature see Felix Victor Birch-Hirschfeld, 'Die neuern pathologisch-anatomischen Untersuchungen ueber krankmachende Schmarotzerpilze', Schmidts Jb. Med., 1872, 155: 97-109. 


\section{Koch's postulates in relation to the work of Henle and Klebs}

entirely compatible with Virchow's research programme. In 1872, however, Klebs began focusing on the external causal agents that Virchow had generally ignored. Klebs' first major paper dealt with the pathology of gunshot wounds, ${ }^{42}$ and, according to Koch, contained "the first attempt to demonstrate a causal connexion between bacteria and the infected wound diseases" (i.65). Over the next few years, Klebs published other papers attempting to identify bacteria as the external causal agents responsible for many infectious diseases. He became progressively more critical of pathological anatomy and especially of Virchow.

In his 1872 paper, Klebs observed that "tracing the invasion and the course of the micro-organisms can make causality probable, but the crucial experiment is to isolate the efficient cause and allow it to operate on the organism." 43 In 1875, he observed that if one could show that "inflammation and other reactive changes follow, step by step, the spread of the schistomycetes, then it is logical to infer a causal relation rather than a simple coincidence."44 Klebs pointed out that experimental evidence could support the same conclusion. To obtain such evidence, one must "isolate substances from the body and use them to induce further cases of infection." Klebs claimed to have followed both approaches and to have obtained mutually supporting results. His papers and his procedures for establishing causality were widely known and discussed. ${ }^{45}$

During the middle 1870 s, several researchers tried to prove that specific organisms were causal agents by isolating and inoculating them. In a text that Koch frequently cited in his 1878 papers on infected wounds, Felix Victor Birch-Hirschfeld discussed two strategies for establishing causality. He observed that Klebs and others tried to explain the pathological significance of micro-organisms by correlating the advancing parasites with the sequence of morbid changes. ${ }^{48}$ According to Birch-Hirschfeld, the recognition that this was inconclusive led to experiments in which "bacteria were isolated in various ways from the liquid constituents of infectious substances. One then compared the results of inoculating with isolated bacteria and with the other liquid materials." ${ }^{47}$ These two strategies are exactly those discussed in Klebs' papers. Birch-Hirschfeld's survey, as well as the primary literature, shows that these strategies were common in medical research in the late 1870s. Those who used these strategies frequently mentioned Henle's conjecture that micro-organisms could cause diseases; ${ }^{48}$ some also mentioned Mayrhofer or

\footnotetext{
${ }^{42}$ Edwin Klebs, Beiträge zur pathologischen Anatomie der Schusswunden, Leipzig, Vogel, 1872.

43 Ibid., p. 105.

4 Edwin Klebs, 'Beiträge zur Kenntniss der pathogenen Schistomyceten', Arch. Path. Pharm., 1875, 3: 305-324, p. 321.

${ }^{45}$ For a few of the many examples see, F. Steudener, 'Ueber pflanzliche Organismen als Krankheitserreger', Samml. klin. Vortr., 1872, Innere Medicin no. 14, 38: 283-308, p. 300; Leopold Landau, 'Zur Aetiologie der Wundkrankheiten', Arch. klin. Chir., 1874, 17: 527-554, p. 529; Birch-Hirschfeld, op. cit., note 41 above, p. 98 (Birch-Hirschfeld called Klebs' work “epochmaking"); and Max Schüller, 'Experimental Beiträge zum Studium der septischen Infection', Dt. Z. Chir., 1876, 6: 113-190, p. 160.

${ }^{46}$ Felix Victor Birch-Hirschfeld, Lehrbuch der pathologischen Anatomie, Leipzig, F.C.W Vogel, 1877, pp. $233 \mathrm{f}$.

47 Ibid., p. 236.

${ }^{48}$ See, for example, Leopold Landau, 'Ueber puerperal Erkrankungen', Arch. Gynaek., 1874, 6: 147-188, p. 174.
} 


\section{K. Codell Carter}

Klebs as the first to have used these strategies to obtain experimental evidence of causality. ${ }^{49}$

In 1877, Klebs addressed a plenary session of the Gesellschaft deutscher Naturforscher und Aerzte on the subject of 'The revolutions in medical opinions in the last three decades' ${ }^{50} \mathrm{He}$ argued that recent advances in medicine resulted from associating specific diseases with particular disease agents, and identified three procedures as relevant in establishing disease causation: (i) anatomical investigations of diseased organs; (ii) the isolation and cultivation of disease germs; and (iii) the initiation of new cases of the same disease by conveying germs to healthy animals. ${ }^{51}$ Klebs mentioned "two ways that can be followed to establish the significance of organisms in the generation of infectious diseases. (i) If organisms are identified that are well characterized and that are found exclusively in the given disease process, anatomical evidence can be conclusive. (ii) If the form of the organisms provides no certain point of departure, it can be decisive to convey the disease by means of organisms that have been isolated and cultivated outside the body." 52 This lecture, which was reviewed in general medical literature and became well known in German medical circles ${ }^{53}$ contains many ideas that figured in Klebs' earlier papers. As before, he regarded the two "ways" as independent and comparably effective. In the 1877 lecture, however, the way that is to be used depends on whether or not the organism in question is well characterized and absent from other disease processes. This condition, which does not appear explicitly in Klebs' earlier papers, is almost precisely I.4. If this condition is met, one is to show that the morbid alterations of the disease correspond to the distribution and concentration of the organisms-a requirement similar to $1.2{ }^{54} \mathrm{Obviously}$, it is only possible to confirm I.2 if the organisms can be identified. Klebs' second way, which can be used even if the organisms are not well characterized, is isolation and inoculation. This way is precisely T.4 and T.5. In this paper, therefore, Klebs identified Koch's two major weak sufficiency criteria; Klebs' two ways correspond to the first two versions of Koch's postulates.

Klebs' procedures for establishing causality are also similar to Virchow and Henle's strategies. He established causality by observation and by animal experiments, and, in some papers, regarded experiments as most decisive. Klebs had been Virchow's pupil, and it is possible that his procedure for establishing causality was a conscious application of Virchow's general research programme. Moreover, Klebs frequently mentioned Henle's conjecture that micro-organisms may cause

\footnotetext{
${ }^{49}$ Ibid., p. 529; Johannes Orth, 'Untersuchungen über Puerperalfieber', Virchows Arch. path. Anat. Physiol., 1873, 58: 473-460; Friedrich Sander, 'Die Bakterienfrage zu London und Berlin', Dt. med. Wschr., 1877, 1: 8-10; David Haussmann, 'Untersuchungen und Versuche über die Entstehung der übertragbaren Krankheiten des Wochenbettes’, Btrg. Geburtsh. Gynaek., 1874-5, 3: 311-421, pp. 312, 351.

${ }^{50}$ Edwin Klebs, 'Ueber die Umgestaltung der medicinischen Anschauungen in den letzten drei Jahrzenhten', Versammlung deutscher Naturforscher und Aerzte in Munchen, Leipzig, Vogel, 1878.

${ }^{51}$ Ibid., p. 49.

52 Ibid., p. 51.

${ }^{53}$ For example, Klebs' lecture was reviewed in the Berl. klin. Wschr, 1877, 14: 594.

54 The conditions are similar but not exactly the same. Koch stipulated that the advance of the micro-organisms must explain the disease phenomena, Klebs required only that it correspond to the development of the disease.
} 


\section{Koch's postulates in relation to the work of Henle and Klebs}

diseases. In his 1877 paper, Klebs observed that Henle's Pathologische Untersuchungen, in which Henle conjectured that micro-organisms could cause disease and mentioned his criterion for proving causality, had not received adequate attention.$^{55}$ Klebs may also have known Henle's criterion for proving causality.

Of course, there were important differences between Klebs and the earlier pathological anatomists. Klebs noted that "Henle recognized, as the causes of disease, only universal physical and chemical influences, the life impulses, the same factors that have often been identified by others who wrote before and after him. The concept of a specific cause of a disease, which is absolutely destructive of life, is alien to him as to most other pathologists." ${ }^{56}$ Klebs mentioned that this was true of Virchow. Klebs criticized the earlier preoccupation with internal disease processes. While Klebs' causal criteria may have been based, in part, on the writings of Virchow and Henle, Klebs realized that his application of those criteria was quite unlike that of his predecessors.

Viewed in this light, Klebs' procedures for establishing causality can be seen as part of a broad tradition that extends back at least into the 1840s. This tradition included Henle's conjecture that micro-organisms cause diseases, and it was clearly compatible with, if not directly dictated by, the basic research strategy of pathological anatomy. We have seen that Koch's weak sufficiency criteria were identical to the criteria that emerged from this tradition; we will now examine the evidence that this tradition was the source of Koch's sufficiency criteria.

Many writers have assumed that at least T.4 and T.5 came directly from Koch's teacher, Jacob Henle. Whether or not Koch was aware of Henle's criterion, there are reasons for doubting that Henle was Koch's primary source for these ideas. First, while Koch admitted that he owed Henle a great debt of gratitude (i.3), he never suggested that Henle had influenced his thinking about causal criteria or even his general interest in bacteriology. Indeed, Koch wrote that he received no encouragement to study bacteriology while he was a student at Göttingen; "bacteriology did not exist at that time" (i.3). The recollections of Elie Metchnikoff, who came to Göttingen to work with Henle just at the time Koch was graduating, confirm Koch's remark. "When, in 1866, I worked under Henle, in Göttingen, at a time when there were serious investigations on the microscopic agents of infectious disease he remained indifferent and ... at no time did the question of contagious disease come up in his laboratory." 57

Second, in his early work on anthrax Koch isolated relatively pure cultures of anthrax bacilli and inoculated them into test animals. However, at that time, Koch seems not to have regarded this procedure as particularly significant in establishing disease causality. The causal arguments in his early anthrax papers stressed necessity rather than sufficiency. The first weak sufficiency criterion appeared in his long paper on infected wounds, and Koch first used isolation and inoculation as a weak sufficiency criterion in his 1882 tuberculosis papers. If one assumes Koch adopted

ss Klebs, op. cit., note 50 above, p. 47.

s6 Ibid., p. 46.

${ }^{57}$ Quoted in Hubert A. Lechevalier and Morris Solotorovsky, Three centuries of microbiology, New York, Dover Publications, 1974, p. 65. 


\section{K. Codell Carter}

T.4 and T.5 directly from Henle while he was Henle's student in Göttingen, it is difficult to explain why these or other weak sufficiency criteria were not central in the causal arguments of his early papers.

When Koch began studying anthrax as a district physician in Wollstein, he was virtually isolated from everyone else who was studying micro-organisms. In his first anthrax paper, Koch admitted a lack of access to certain important publications (i.13f), and he used reviews and abstracts rather than the original papers. The postulates do not figure in the first anthrax papers or in the summary version of the 1878 paper on infected wounds that he delivered before the Gesellschaft deutscher Naturforscher und Aerzte.

The Gesellschaft was the same society before which Klebs had presented his famous 1877 lecture, and had, in the 1878 meetings, again criticized Virchow's research programme. ${ }^{58}$ Klebs and Koch were often together at these meetings. ${ }^{59}$ Shortly thereafter, Koch published his long paper on wound infections-the paper containing the first version of the postulates-and he cited several of Klebs' essays including all three of those discussed above (i.65f, 70), as well as one of the procedures by which Klebs sought to identify disease agents (i. 70). Koch credited Klebs with having been the first to attempt to prove that micro-organisms caused infected wound diseases (i. 65). It may have been because of Klebs' influence that Koch began to think explicitly about causal criteria at the time of the 1878 meetings.

In any case, Koch cited Klebs in several papers published in the early 1880 s (i.133, 158f, 183). In his famous tuberculosis papers of 1881 and 1884 , he cited Klebs but did not associate him with T.4 and T.5 (i.433, 437, 468, 525, 529). In Koch's less famous and less comonly read second 1882 paper on tuberculosis, however, the association was explicit. He mentioned that various methods had been used in attempting to prove causality, but that "the best method, the method used by everyone who has been seriously occupied with these investigations, was introduced and refined by Klebs." (i. 446). He described this method as, first, producing successive pure cultures to separate the parasite from all disease products and, second, inoculating the isolated parasites into test animals. Koch then observed that his own investigations of tuberculosis followed this procedure.

Given that Koch himself acknowledged that Klebs was the source of T.4 and T.5, and given that I.4 as well as T.4 and T.5 were so similar to Klebs' two ways for establishing causality, it seems likely that Klebs was the primary source for Koch's weak sufficiency criteria. Koch was a consummate technician, and his experimental work certainly satisfied Klebs' criteria more rigorously than Klebs himself, or anyone else, had been able to do. However, this should not blind us to the possibility that Koch did not originate the strategy that his own experimental work followed.

\footnotetext{
${ }^{58}$ Edwin Klebs, 'Ueber Cellularpathologie und Infectionskrankheiten', Tageblatt der 51 Versammlung deutscher Naturforscher und Aerzte, Kassel, Baier und Lewalter, 1878, pp. 127-134.

${ }^{39}$ Bruno Heymann, Robert Koch, Leipzig, Akademische Verlagsgesellschaft, 1932, p. 236.
} 


\section{Koch's postulates in relation to the work of Henle and Klebs}

\section{III}

I have argued that Koch's weak sufficiency criteria were derived from Edwin Klebs and that Klebs' views were part of a broad tradition of causal thinking that was firmly grounded in the basic research programme of pathological anatomy. We must now consider an important difference between Koch's postulates and the causal criteria espoused by Klebs, Virchow, and Henle.

We have seen that Koch's early aetiological papers contain no sufficiency criteria at all. Even in the papers in which he stated the postulates, he did not use one particular sufficiency criterion; instead, we find a series of different criteria, none of which is used in more than a few papers. Koch never suggested that any one of his weak sufficiency criteria was itself adequate to prove causality. Each time he stated such a criterion he also stipulated that the causal organism must also be necessary and that it must explain the diseases phenomena. Even in the 1882 and 1884 papers, the papers in which Koch described T.4 and T.5 as most decisive, he stated these other conditions and gave evidence that they were satisfied. One gains the impression that T.4 and T.5, the criteria usually emphasized by Koch's commentators, represent almost a temporary anomaly in Koch's thinking-an anomaly occasioned by his contract with Klebs. Considering his writings as a whole, Koch was more consistently and, perhaps, more fundamentally committed to causal necessity than to any form of sufficiency. ${ }^{60}$ In contrast to Koch, neither Henle, Virchow, Klebs, nor any of Koch's contemporaries who used Klebs' criteria required that causal agents be necessary. Apparently, they all regarded the weak sufficiency criteria alone as conclusive. We will confirm these claims by reviewing the writings of various researchers.

In his only explicit consideration of causal criteria, Henle wrote that "one could prove empirically that [the organisms] were really effective only if one could isolate the contagious organisms from the contagious fluids, and then observe the powers of each separately." ${ }^{61}$ Nowhere in the context of this passage did Henle suggest that any other conditions must be satisfied in demonstrating causality. Although he observed that even if living organisms were regularly identified in diseased bodies, this would not prove that the organisms were more than harmless saprophytes, there is no reason to interpret this remark as stipulating that only organisms that are always identified in a certain disease process can be causal agents. ${ }^{62}$ Indeed, the whole point of the passage is that inducing disease by inoculating pure organisms conclusively demonstrates that the organisms are the cause. This quotation is from a chapter entitled 'Miasmata and Contagia'; while some passages in this chapter suggest that "contagia" may be necessary for some diseases, the discussion, taken as whole, is far from conclusive. From his discussion it is obvious that, in addition to miasmata and contagia, Henle recognized both various physical and chemical properties of the air, for example, unusual or variable pressure and temperature ${ }^{63}$ and other so-called

\footnotetext{
${ }^{60}$ This claim can also be supported by examining the papers that Koch wrote after 1890 , the year in which he last mentioned the postulates. From that time on, necessity criteria dominate his causal reasoning.

${ }^{61}$ Henle, op. cit., note 35 above.

${ }_{62}$ Yet this is how Henle is sometimes interpreted. See, for example, Anton Mayr and Barbara Bibrack, 'Ursache-Wirkungs-Relationen bei Infektionskrankheiten', Zbl. Bakt. Hyg., 1974, 226: 168-183, p. 173.

${ }^{63}$ Henle, op. cit., note 35 above, pp. 910-913.
} 


\section{K. Codell Carter}

sporadic factors ${ }^{64}$ as possible causes of such diseases as cholera, plague, or puerperal fever. For example, he observed that "external and internal exanthemata can arise from many other local and general causes, apart from an infective matter, and fever can be added to these just as to the miasmatic-contagious exanthemata." ${ }^{65}$ This, of course, was entirely compatible with orthodox medical thought in the 1840s. For example, at that time, typical European obstetricians identified both contagia and epidemic atmospheric influences as well as general deprivation, worry, shame, attempted abortion, fear of death, dietary disorders, exposure to cold, local miasmas, difficult delivery, and retention and decomposition of the placenta as possible causes of puerperal fever ${ }^{66}$-one of the diseases that Henle discussed in this section of his work. In the context of the early 1840 s, a discussion of contagia or even of ways to prove that a particular contagion causes a specific disease certainly does not show that the author regarded contagia as necessary even for diseases that were generally recognized as contagious. To draw such an inference is to interpret Henle in the light of subsequent developments. So far as I can determine, Henle never stipulated unambiguously that causal agents must be necessary for the diseases they cause, indeed, nothing Henle wrote provides an unambigous basis for any of Koch's causal criteria other than T.4 and T.5. At the very least, therefore, it is a gross exaggeration to speak of the Henle-Koch postulates.

Similar observations hold for Rudolf Virchow. As Klebs pointed out, ${ }^{67}$ and as Virchow himself admitted ${ }^{68}$ the pathologists were much less interested in external causal agents than in internal disease processes. Virchow, too, was primarily interested in the causal sequence of lesions that constituted a given disease process, although he claimed to have given more emphasis than most pathologists to external causes. ${ }^{69}$ However, Virchow's discussions of criteria for causation never suggested that any causes, internal or external, must be necessary as well as sufficient, and his few scattered remarks on external causes clearly suggest that he accepted the orthodox view that most diseases could originate from a range of unrelated external factors, no one of which was necessary. ${ }^{70}$ Thus, there is no evidence that Virchow would have accepted Koch's first postulate.

In 1877, Julius Cohnheim, a prominent pathologist and one of Virchow's pupils,

64 Ibid., p. 919.

${ }^{65}$ Ibid., p. 964 . Henle made related remarks in other places, but he was not entirely consistent. Cf. pp. 955, 966.

${ }^{6 B}$ See, for example, the causal discussions in Eduard Lumpe, 'Die Leistungen der neuesten Zeit in der Gynaekologie', Z. k. k. Ges. Aerzte Wien, 1845, 1: 341-371; Eduard Martin, 'Ueber den gegenwärtigen Stand der Lehre vom Puerperalfieber und die nächste Aufgabe für die fernerer Bearbeitung derselben', $Z$. rat. Med., 1846, 5: 1-44; or Braun, op. cit., note 40 above.

${ }^{67}$ Klebs, op. cit., note 50 above, p. 46, note 58 above, pp. $133 \mathrm{f}$.

${ }_{68}$ Virchow, op. cit., note 34 above.

69 Ibid.

${ }^{70}$ For example, in an 1861 discussion of puerperal fever, Virchow insisted that it was essential to distinguish cases of puerperal fever "which clearly bear an epidemic character" from cases "in which local infection can be demonstrated". He also illustrated the importance of predisposition by this analogy: "Just as a man who is overheated will contract facial erysipelas if he exposes his face to a draught, so too the puerpera, overheated by the process of delivery, can become ill if her uterus is chilled." These remarks were made in a discussion which took place at the thirty-sixth meeting of the Gesellschaft deutscher Naturforscher und Aerzte. The discussion was reported in the Mschr. Gebursk. Frauenkr., 1861, 18: 278-380. 


\section{Koch's postulates in relation to the work of Henle and Klebs}

published the first volume of a textbook on pathological anatomy. ${ }^{71}$ Cohnheim's conceptions of disease and disease causation were very similar to Virchow's. In this book, as in his other writings, Cohnheim emphasized the experimental method in gaining an understanding of causation and of disease processes. ${ }^{72}$ Cohnheim was unusually sensitive to the significance of research into the relation between micro-organisms and disease. Indeed, he concluded that the recently gained understanding of the parasitic nature of trichinosis should induce physicians "to seek a similar explanation for the infectious diseases". ${ }^{73}$ However, Cohnheim's discussions of aetiology are perfectly compatible with earlier notions. He observed that aetiology is an unbounded domain including "cosmic physics, meterology and geology no less than the social sciences [Socialwissenschaften] and chemistry as well as botany and zoology." "74 $\mathrm{He}$ also observed that aetiological discussions in common textbooks included everything "from temperament to beds, from air electricity to fungi and fleas, from inheritance to drinks." ${ }^{\prime \prime 5}$ Cohnheim's discussions of specific diseases illustrate perfectly these general remarks. For example, as causes of "local anaemia", he listed too high a resistance in the circulation, which can be caused by low temperatures, stimulation of the vasomotor system by nerves or by certain poisons such as opium or lead, as well as morbid changes in the artery walls from calcification, reduction in elasticity of the veins, thrombosis, strictures, and abnormal pressure..$^{76}$ Thus, Cohnheim traced the specific abnormality to a variety of unrelated external causes, no one of which was necessary for all cases of the disease.

As one would expect, Henle, Virchow, Cohnheim, and their colleagues focused heavily on sufficiency criteria for disease causality. Here, for example, are the causal criteria that appeared in an 1850 monograph on cholera: "In order for any purported cause to be recognized as the actual cause of a disease, we must always be able to answer the following questions affirmatively: does this cause always have the same effect? As an experiment can one always bring about the disease in this way? In those cases in which the cause does not bring about the specified disease, can the same reason for failure always be identified?"'77 Each of these conditions would be satisfied by a cause that was sufficient or weakly sufficient, but none of them would be satisfied by a cause that was necessary and not sufficient. Here, as a second example, is an excerpt from an 1878 essay by Cohnheim entitled 'On the role of pathological anatomy'. Cohnheim observed, "A really conclusive proof of a causal relation ... can be given only when one succeeds, by use of the supposed cause, in generating at will the desired effect, that is, the specific disease .... There can be no doubt about the causal relation once one ... brings about the same alteration in rabbits or dogs

\footnotetext{
71 Julius Friedrich Cohnheim, Vorlesungen über allgemeine Pathologie, Berlin, August Hirschwald, 1877. The second volume appeared in 1880 .

${ }^{72}$ For example, see Cohnheim's lecture 'Ueber die Aufgaben der pathologischen Anatomie', reprinted in his Gesammelte Abhandlungen, Berlin, August Hirschwald, 1885, pp. 605-622.

${ }^{73}$ Cohnheim, op. cit., note 71 above, pp. $251 \mathrm{f}$.

74 Ibid., p. 8.

${ }^{75}$ Ibid., p. 9.

${ }^{76}$ Ibid., p. 80. Causes of "chronic nephritis" include "malaria, constitutional syphilis, chronic lead poisoning, excessive consumption of alcohol, repeated exposure to cold, soaking wet conditions of part of all the body, for example, of the feet" (vol. 2, p. 336).

${ }^{77}$ Joseph Hamernik, Die Cholera epidemica, Prague, Calve, 1850, pp. $247 \mathrm{f}$.
} 


\section{K. Codell Carter}

that the [cause is supposed to have brought about in human cases of illness]." aetiological literature of these decades contains many similar passages. Here again, obviously, the issue is exclusively whether the supposed cause is sufficient. The exclusive interest in sufficient rather than necessary causes also explains why physicians in the period repeatedly warned against inferring a common cause from a common effect. ${ }^{79}$

One observes precisely the same priority of interests in the writings of Edwin Klebs. In the papers quoted above, Klebs seems clearly to have regarded isolation and inoculation as conclusive. He never suggested that causal organisms must also be necessary. The closest Klebs ever came to suggesting a necessity criterion is in the following passage from his 1877 lecture: "In every adequately examined disease, particular organisms are found that always function in the same way. This indicates that these organisms stand in an important relation to the disease process. However, that the organisms stand in a causal relation to the disease process follows from the fact, conclusively established for at least some diseases, that conveying the organisms always generates the same disease." even if one interprets it to mean that causal organisms must be found in every case of a given disease, the second sentence clearly shows that Klebs regarded the weak sufficiency criterion alone as the decisive proof that the relation between the organism and the disease is causal. ${ }^{81}$

In his 1877 lecture, Klebs criticized Henle for failing to recognize the existence of what Klebs called "specific causes". "The concept of a specific cause of a disease, which is absolutely destructive of life, is entirely alien to [Henle] as to most other pathologists." 82 One may think that Klebs' use of the term "specific causes" provides some evidence that he regarded causal agents as necessary. At least this term is now often used in this sense. ${ }^{83}$ However, since Klebs never explicitly asserted that causes of diseases must be necessary, it seems more plausible to interpret his use of this term in a different way. As the context of this passage shows, Klebs was criticizing Henle for thinking that the causes of diseases were simply ordinary processes occurring

${ }^{78}$ Cohnheim, op. cit., note 72 above, pp. 615.

79 " Since it is in the nature of the nervous system to react in the same manner to the most varied stimuli, to infer similar causes from similar effects as necessary as it otherwise is, is not entirely dependable." (Henle, op. cit., note 35 above, p. 955); In a discussion of pathological changes in the body, Edward William Murphy observed that "identity of effect by no means proves one and the same cause." ('Puerperal fever', Dublin Quart. J. Med. Sci., 1857, 24: 1-30, p. 4.)

${ }^{80}$ Klebs, op. cit., note 50 above, p. 50.

${ }^{81}$ We have seen that Klebs charged Virchow with ignoring external cause and focusing exclusively on the internal causal sequence of the disease process. For his part, Virchow responded that by ignoring internal disposition, Klebs was in danger of going to the opposite extreme. "Evidently Klebs is ... of the opinion that the internal arrangement of the tissues is irrelevant [in determining the response to an external cause], or, expressed in the terms of universal pathology, that the external cause is an Agens Causa sufficiens for all the consequences." (Virchow, op. cit., note 34 above, p. 9). But, of course, Virchow did not accuse Klebs of an interest in necessary causes.

${ }^{82}$ Klebs, op. cit., note 50 above, p. 46.

83 ' $\mathrm{By}$ 'specific causal factor' is meant the enviromental factor or 'remote' cause-cause outside the body-without which there could be no disease. Other environmental factors might or might not be present but this factor was necessary for the disease to occur." Richmond, op. cit., note 5 above, p. 84. Lester S. King says essentially the same thing in his discussion of disease causation in The philosophy of medicine, Cambridge, Mass., Harvard University Press, 1978, pp. 209-213. 


\section{Koch's postulates in relation to the work of Henle and Klebs}

under extreme or abnormal conditions, and for failing to recognize that causes of disease could be specific in the sense of being totally unlike ordinary life processes-the causes of diseases were specific to disease processes. This sense of specific, which seems most suitable given the rest of Klebs' discussion, is perfectly compatible with the possibility that the cause of a disease is sufficient or weakly sufficient but not necessary.

Koch's postulates require that the cause of a given disease must be necessary and, in one way or another, sufficient or weakly sufficient for the disease. On the other hand, most of those who seem to have influenced Koch's causal thinking focused on causes that were weakly sufficient but not necessary. I certainly do not wish to suggest that no one in the 1870 s and 1880 s was interested in necessary causes of disease. Indeed, in an earlier paper I examined a large body of literature that focused precisely on necessary causes. ${ }^{84}$ Here I wish only to establish that, in contrast to Koch, many medical writers in the middle of the nineteenth century gave primary attention to causal sufficiency and often tended to ignore necessity. This seems to have been particularly true of Henle, Virchow, Klebs, and of several other researchers who contributed to the research tradition from which Koch's weak sufficiency criteria were probably drawn.

As we observed above, one generally seeks a sufficient cause if one wants to bring about some state of affairs or to explain why something has happened. Thus, we can understand one factor that focused the attention of pathological anatomists on sufficient causes; one of their objectives was to demonstrate causal relations by inducing disease processes in animals. On the other hand, if one wants to prevent or eliminate some state of affairs, one seeks a necessary cause. Given causes that are sufficient but not necessary it is virtually impossible to undertake effective steps to prevent or to eliminate an undesired effect. Thus, if one assumes that the goal of medicine is to prevent or to eliminate disease, one would expect that physicians and medical researchers would be primarily interested in necessary causes (whether or not they are also sufficient). As we have seen, Koch always required that the cause of a disease must be necessary, and he usually required that it must also be sufficient or weakly sufficient. By contrast, the causes that Henle, Virchow, Klebs, and several other researchers identified were sufficient or weakly sufficient but not necessary. Thus, this rather subtle change in talk about disease causality may reflect fundamental changes in the purposes and goals of medicine as an institution-changes that are to be dated to about the middle of the nineteenth century.

In his 1877 and 1878 lectures, Edwin Klebs observed that while pathological anatomy had made great strides in describing and explaining disease processes, it had contributed almost nothing to the control of disease ${ }^{85}$ Whether or not Klebs' criticism was accurate, his remarks suggest that pathological anatomy had seriously failed to satisfy earlier expectations. As Klebs himself clearly recognized, this failure was partially a consequence of the pathologists' conceptions of disease causality.

\footnotetext{
${ }^{84}$ K. Codell Carter, 'Ignaz Semmelweis, Carl Mayrhofer, and the rise of germ theory', Med. Hist., 1985 , 29: 33-53.

${ }^{85}$ Klebs, op. cit., note 50 above, p. 47, op. cit., note 58 above, pp. $133 \mathrm{f}$.
} 


\section{K. Codell Carter}

Klebs' own recommendation was that instead of concerning themselves with internal causes of disease processes, physicians should investigate the external causes that initiated each disease as a whole. Klebs, of course, believed that micro-organisms were external causes that deserved primary attention. Unfortunately, his recommendation was not adequate to solve the problem. He urged physicians to think of a new range of causes, but his conception of the causes of disease was essentially the same as that of the pathological anatomists, as sufficient causes of particular events. In fact, what was required was not simply a new application of this existing conception, but a subtle and yet profound change in the basic conception itself. What was required was precisely what Koch's first postulate provided- the concept of a necessary cause. 